ERR A T UM

Vera Höllriegl • Pascale Louvat • Eckhard Werner •

Paul Roth • Peter Schramel • Iris Wendler •

Norbert Felgenhauer • Thomas Zilker

\title{
Studies of strontium biokinetics in humans
}

\section{Part 2: Uptake of strontium from aqueous solutions and labelled foodstuffs}

Published online: 1 July 2003

(C) Springer-Verlag 2003

\section{Radiat Environ Biophys (2002) 41:281-287}

The wrong version of Appendix was published. The correct Appendix appears here.

\section{Appendix}

Derivation of the $\mathrm{f}_{1}$ equation:

$\mathrm{f}_{1}=\frac{z_{86 p o}}{z_{84 i v}} \cdot \frac{m_{84 i v}}{m_{86 p o}}$

$\frac{z_{86 p o}}{z_{84 i v}}=\frac{\left(\frac{z_{84}}{z_{88}}\right) \cdot\left(h_{86} \cdot k_{88}-k_{86}\right)+\left(\frac{z_{86}}{z_{88}}\right) \cdot\left(1-h_{84} \cdot k_{88}\right)+h_{84} \cdot k_{86}-h_{86}}{\left(\frac{z_{84}}{z_{88}}\right) \cdot\left(1-h_{86} \cdot l_{88}\right)+\left(\frac{z_{86}}{z_{88}}\right) \cdot\left(h_{84} \cdot l_{88}-l_{84}\right)+h_{86} \cdot l_{84}-h_{84}}$

where $\frac{z_{84}}{z_{88}}, \frac{z_{86}}{z_{88}}$ are the ratios of strontium isotopes in blood and urine, measured by TI-MS

$\mathrm{h}_{84}, \mathrm{~h}_{86}:$ ratios of isotopes ${ }^{84} \mathrm{Sr}$, and ${ }^{86} \mathrm{Sr}$ in relation to natural ${ }^{88} \mathrm{Sr}$

$\mathrm{k}_{86}, \mathrm{k}_{88}$ : ratios of isotopes ${ }^{86} \mathrm{Sr}$, and ${ }^{88} \mathrm{Sr}$ in relation to

${ }^{84} \mathrm{Sr}$ in the intravenous tracer

The online version of the original article can be found at http:// dx.doi.org/10.1007/s00411-002-0175-2

V. Höllriegl (®) · P. Louvat · E. Werner · P. Roth

Institute of Radiation Protection,

GSF National Research Center for Environment and Health,

Ingolstädter Landstrasse 1, 85764 Neuherberg, Germany

e-mail: vera.hoellriegl@gsf.de

Tel.: ++49- 89- 31873219

Fax: ++49- 89- 31872517

P. Schramel · I. Wendler Institute of Ecological Chemistry,

GSF National Research Center for Environment and Health, Ingolstädter Landstrasse 1, 85764 Neuherberg, Germany

N. Felgenhauer $\cdot$ T. Zilker

Department of Toxicology,

II. Medical Clinic of the Technical University Munich,

81675 Munich, Germany
$1_{84}, 1_{88}:$ ratios of isotopes ${ }^{84} \mathrm{Sr}$, and ${ }^{88} \mathrm{Sr}$ in relation to ${ }^{86} \mathrm{Sr}$ in the oral tracer

$\mathrm{m}_{84}, \mathrm{~m}_{86}$ : amounts of the isotopes ${ }^{84} \mathrm{Sr}$ and ${ }^{86} \mathrm{Sr}$ as administered tracers, multiplied with the enrichment factor (enrichment of ${ }^{84} \mathrm{Sr}: 76.4 \%$, of ${ }^{86} \mathrm{Sr}$ : $95.70 \%$, see Table 2) iv=intravenous, po=per oral.

For calculation of factors $\mathrm{h}_{84,86}, \mathrm{k}_{86,88}, 1_{84,88}$ : take the corresponding data given in Table 2 (e.g.: $\mathrm{h}_{84}=$ ratio of 0.56 to 82.58 ).

Considering the composition of the measured values at masses $\mathrm{z}_{84}, \mathrm{z}_{86}$ and $\mathrm{z}_{88}$ :

$$
\begin{aligned}
& z_{84}=z_{84 n a t}+z_{84 i v}+z_{84 p o} \\
& z_{86}=z_{86 n a t}+z_{86 i v}+z_{86 p o} \\
& z_{88}=z_{88 n a t}+z_{88 i v}+z_{88 p o} \\
& \text { It is: }
\end{aligned}
$$

$z_{84 n a t}=h_{84} \cdot z_{88 n a t}$

$h_{84}=\frac{z_{84 n a t}}{z_{88 n a t}}$

$z_{86 n a t}=h_{86} \cdot z_{88 n a t}$

$h_{86}=\frac{z_{86 n a t}}{z_{88 n a t}}$

$z_{86 i v}=k_{86} \cdot z_{84 i v}$

$k_{86}=\frac{z_{86 i v}}{z_{84 i v}}$

$z_{88 i v}=k_{88} \cdot z_{84 i v}$

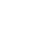




$$
\begin{aligned}
& k_{88}=\frac{z_{88 i v}}{z_{84 i v}} \\
& z_{84 p o}=l_{84} \cdot z_{86 p o} \\
& l_{84}=\frac{z_{84 p o}}{z_{86 p o}} \\
& z_{88 p o}=l_{88} \cdot z_{86 p o} \\
& l_{88}=\frac{z_{88 p o}}{z_{86 p o}}
\end{aligned}
$$

(7a) and the ratio of $\frac{z_{86}}{z_{88}}$ is set equal to ratio of Eq. (2) to

(8a) and solve Eq. (11) for $\mathrm{Z}_{88 \text { nat }}$ (taking into account Eqs. $4-9 \mathrm{a}$ ). Solve Eq. (10) for Z88nat

The ratio of $\frac{z_{84}}{z_{88}}$ is set equal to ratio of Eq. (1) to Eq. (3)
(9a) Finally, set Eq. (12) equal to Eq. (13), and solve for $\frac{z_{86 p o}}{z_{84 i v}}$.

